\title{
Post-infection irritable bowel syndrome or tropical sprue: A paradigm shift
}

Uday C. Ghoshal

Department of Gastroenterology, Sanjay Gandhi Postgraduate Institute of Medical Sciences, Lucknow - 226 014, Uttar Pradesh, India

\section{RESUMEN}

Después de padecer gastroenteritis aguda, el 10-30\% de los pacientes desarrollan IBS postinfección (PI-IBS). La malabsorción de la mucosa también se ha observado en la investigación de laboratorio después de la gastroenteritis aguda (llamada síndrome de malabsorción postinfecciosa [PI-MAS], brote epidémico tropical). Las dos condiciones pueden sùperponerse. La literatura proporciona alguna evidencia para apoyar la presencia de PI-MAS en un porcentaje de pacientes con PI-IBS. En un estudio de Bangladesh, el PI-MAS, diagnosticado por resultados anormales en al menos dos de las tres pruebas (d-xilosa, grasa fecal, biopsia duodenal), estuvo presente en el 9\% de los casos con PI-IBS. En un estudio entre el personal militar estadounidense, la odds ratio de gastroenteritis aguda previa fue de 6,48 entre los diagnosticados como esprúe tropical. Existe una superposición significativa en la patogénesis del PI-IBS y el PI-MAS. A pesar de la escasez de datos, la superposición entre el PI-SII y el esprúe tropical puede tener implicaciones, al sugerir una base orgánica definida del SII y en el papel del tratamiento periférico dirigido para este trastorno. También se sugiere que la malabsorción de la mucosa debe ser excluida por investigaciones que incluyan histología del intestino delgado además de criterios de PI-IBS. De hecho, la malabsorción de la mucosa puede ser un mecanismo subyacente en un subconjunto de SII, particularmente el que tiene subtipo predominante de diarrea, en especial después de la gastroenteritis infecciosa aguda (SII-PI). Se necesitan más estudios sobre este tema. NeuroGastroLatam Rev. 2018;2:37-46) Corresponding author: Uday C. Ghoshal, udayghoshal@gmail.com

Palabras clave: Trastornos intestinales funcionales. Esprúe tropical. Infección gastrointestinal. Microbiota intestinal. Diarrea crónica. 


\section{ABSTRACT}

After acute gastroenteritis, 10-30\% of patients develop post-infection irritable bowel syndrome (PI-IBS). Mucosal malabsorption has also been shown on laboratory investigation after acute gastroenteritis (called post-infectious malabsorption syndrome [PI-MAS], epidemic tropical sprue [TS]). The two conditions might overlap. Literature provides some evidence to support the presence of PI-MAS in a proportion of patients with PI-IBS. In a Bangladeshi study, PI-MAS, diagnosed by abnormal results in at least two of the three tests (D-xylose, fecal fat, and duodenal biopsy), was present in $9 \%$ with PI-IBS. In a study among American military personnel, the odds ratio of prior acute gastroenteritis was 6.48 among those diagnosed as TS. There is significant overlap in the pathogenesis of PI-IBS and PI-MAS. In spite of scanty data, overlap between PI-IBS and TS may have implication by suggesting definite organic basis of IBS, and the role of peripherally directed treatment for this disorder. It is also suggested that mucosal malabsorption should be excluded by appropriate investigations including small intestinal histology and this point should be added to the PI-IBS criteria. In fact, mucosal malabsorption may be an underlying mechanism in a subset of IBS, particularly the one with diarrhea-predominant subtype, particularly following acute infectious gastroenteritis (PI-IBS). More studies are needed on this issue.

Key words: Functional bowel disorders. Tropical sprue. Gastrointestinal infection. Gut microbiota. Chronic diarrhea.

\section{INTRODUCTION}

After an acute attack on infectious gastroenteritis, about $10-30 \%$ of patients continue to experience chronic gastrointestinal symptoms fulfilling Rome criteria for irritable bowel syndrome (IBS), functional dyspepsia, or an overlap syndrome in the absence of in these conditions previously; this has been named as post-infection IBS (PI-IBS) ${ }^{1}$. Although PIIBS was first described by Stewart et al., about seven decades ago and subsequently ${ }^{2}$, in 1962 by Chaudhary and Truelove ${ }^{3}$, the entity was forgotten by the medical community till 1996, when Gwee et al. reported in a seminal paper from Sheffield, UK, that 20/75 (26.6\%) patients with acute gastroenteritis continued to report gastrointestinal symptoms, which fulfilled Rome criteria for IBS even 6 months following the episode of acute infective gastroenteritis ${ }^{4}$. Since the publication of this paper, several studies have been published reporting the frequency, risk factors, and outcome of this condition both from the Western and the Eastern World (Fig. 1) 1, 1,6. The literature on PI-IBS has been reviewed by the expert committee of the Rome Foundation and diagnostic criteria and algorithm laid down recently ${ }^{7}$.

Several studies reported a higher frequency of the development of PI-IBS among patients with acute infectious gastroenteritis than controls. In an earlier meta-analysis, the incidence of PI-IBS among subjects with a history of 


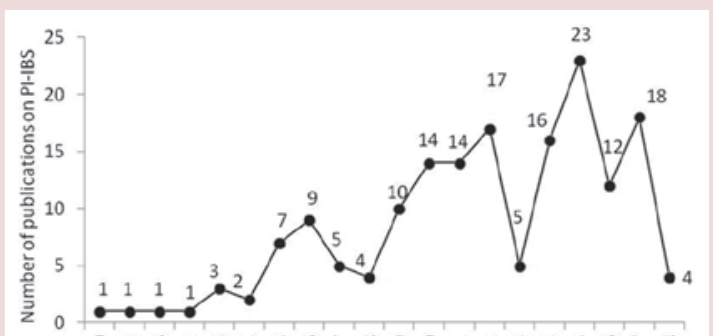

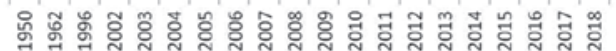

Figura 1. Number of publications on post-infection irritable bowel syndrome since 1950-2018 (PubMed search in March 2018).

traveler's diarrhea was $5.4 \%$ in contrast to an incidence of $1.4 \%$ among healthy subjects ${ }^{8}$. In another recent meta-analysis of 45 studies including 21,421 subjects with acute gastroenteritis, pooled prevalence of IBS 12 months after the episode of enteritis was 10.1\% (95\% confidence interval [CI], 7.2-14.1 $)^{9}$. Several risk factors for the development of IBS following acute gastroenteritis have been identified ${ }^{7}$. These include female gender, adverse life events immediately before enteritis, anxiety and depression at the time of enteritis, severe attack, long-duration diarrhea ( $>7$ days), antibiotic use, invasive disease as evidenced by fever and blood in the stool, weight loss, and some genetic polymorphism. Most patients with PI-IBS have either diarrhea or mixed subtypes of $\operatorname{IBS}^{1,7}$.

\section{POST-INFECTIOUS MALABSORPTION SYNDROME (PI-MAS, TROPICAL SPRUE [TS]]}

TS is defined as a condition characterized by chronic (> 4 weeks) small bowel diarrhea with demonstration of malabsorption of two unrelated substances (e.g., carbohydrates, fat, and Vitamin B12), abnormal small intestinal mucosal histology, in the absence of any other known cause of malabsorption and showing persistent response to treatment with tetracycline, folic acid, and Vitamin $\mathrm{B} 12^{6}$. TS can either be sporadic or epidemic ${ }^{6}$. Several studies recently reported from India showed a sporadic form of TS to be the most common cause of MAS in Indian adults ${ }^{10-12}$. Following acute infectious gastroenteritis, continued liquidity and high frequency of stool may also result from PI-MAS (epidemic form of TS) ${ }^{1}$. Epidemic form of TS was reported among soldiers and prisoners of war in the IndoBurma region during the Second World War ${ }^{13}$ in American military personnel serving in the Philippines ${ }^{14}$ and in Bangladesh ${ }^{15}$. A study from southern India reported more than five decades ago investigated the frequency of the development of PI-MAS (epidemic form of TS) following acute infectious diarrhea in four villages ${ }^{16}$. In one of these four villages, acute infectious gastroenteritis was mostly caused by Salmonella in children and was not followed by continued gastrointestinal symptoms. In another village, enteritis, mostly affecting adults, was characterized by short duration (2-3 days), the absence of fever, vomiting, and absence of bacterial enteropathogen on culture; none of the patients in this village developed symptoms of PI-MAS (TS) at 1-year follow-up. Of the two other villages, in one $20 \%$ continued to have diarrhea at the end of 4 months, and $6 \%$ at the end of 1 year; in the other village, $9 \%$ at the end of 3 months and $5 \%$ at the end of 5 months. A proportion of patients investigated for mucosal malabsorption by D-xylose test, fecal fat, and Vitamin B12 revealed evidence of malabsorption ${ }^{16}$. In a more recent study from Malaysia, of 
59/1985 consecutive patients undergoing duodenal biopsy during an upper gastrointestinal endoscopy, 21 (35.6\%) had partial villous atrophy and were diagnosed as PI-MAS (TS) ${ }^{17}$. Authors suggested that these patients may mimic IBS ${ }^{17}$. TS has recently been reported from Washington, DC, the USA among American military personnel posted mostly in Iraq $^{18}$. In this study conducted over a 13-year period (1999-2012), 47 and 397 military personnel were diagnosed having TS and other types of intestinal malabsorption, respectively ${ }^{18}$. The incidence of TS was $0.24 / 100,000$ person-year (calculated from the number of active military personnel). The odds ratio of prior infective gastroenteritis was 6.48 (95\% CI 2.55-17.81) among patients diagnosed having $\mathrm{TS}^{18}$. In a recent study from Bangladesh, of 345 subjects each with acute gastroenteritis and healthy controls, patients more often developed PI-IBS than controls $(16.5 \%$ vs. $2.6 \%$; $p=0.00$ ). PI-MAS, diagnosed by abnormal results in at least two of the three tests, was present in 2/23 (9\%) patients with PI-IBS ${ }^{19}$. Since all the patients developing PI-IBS were not tested for MAS, it is possible that the frequency of TS might have been underestimated in this study. All these data suggest that following acute infectious gastroenteritis, a proportion of subjects continue to experience gastrointestinal symptoms and may fulfill the diagnostic criteria for IBS. However, symptoms alone would not be able to diagnose intestinal malabsorption among these patients, and hence, appropriate investigations would be the only method to diagnose PI-IBS (TS).

\section{TROPICAL ENTEROPATHY}

Tropical enteropathy, a condition reported in the tropics, is characterized by abnormal villous morphology in the absence of any clinical manifestation including diarrhea among apparently healthy inhabitants ${ }^{1,6}$. Table 1 summarizes the differences between TS and enteropathy ${ }^{6}$. A few studies in the past reported that the villous heights among Indian were shorter than that among British population $^{20}$. However, whether this remains true at present with urbanization and socioeconomic improvement in India needs to be studied further.

Recently, an entity quite similar to tropical enteropathy has been reported among children from multiple countries with a different name, environmental enteric dysfunction ${ }^{21}$. This is characterized by stunted growth, mucosal abnormalities in the small bowel including abnormal permeability and gut dysbiosis ${ }^{21}$.

TABLE 1. Differences between tropical sprue and tropical enteropathy

\begin{tabular}{|l|l|l|}
\hline Features & Tropical sprue & Tropical enteropathy \\
\hline Gastrointestinal symptoms & Present & Absent \\
\hline Natural history & Progressive worsening & Improves or worsens \\
\hline Nutritional deficiency & Common & Less common \\
\hline Migration to a temperate zone & Usually no improvement & Normalization of intestinal abnormalities \\
\hline Response to treatment with folic acid and tetracycline & Dependable improvement in most patients & Variable \\
\hline & & \\
\hline
\end{tabular}


TABLE 2. Comparison between post-infectious tropical malabsorption or epidemic form of TS and post-infection irritable bowel syndrome

\begin{tabular}{|c|c|c|}
\hline Features & $\begin{array}{l}\text { Post-infectious tropical malabsorption } \\
\text { or epidemic form of TS }\end{array}$ & $\begin{array}{l}\text { Post-infection irritable bowel } \\
\text { syndrome }\end{array}$ \\
\hline \multicolumn{3}{|l|}{ Epidemiology } \\
\hline $\begin{array}{l}\text { The frequency of occurrence following an attack of } \\
\text { gastroenteritis }\end{array}$ & $10-20 \%$ & $10-20 \%$ \\
\hline The time period when reported & Five to six decades ago & Mostly last two decades \\
\hline Areas of world from where reported & $\begin{array}{l}\text { Tropics and temperate region (called } \\
\text { tropical and temperate sprue) }\end{array}$ & Temperate regions mainly \\
\hline \multicolumn{3}{|l|}{ Clinical presentation and diagnosis } \\
\hline Predominant clinical feature & $\begin{array}{l}\text { Diarrhea as defined by liquidity and } \\
\text { frequency of stool }\end{array}$ & $\begin{array}{l}\text { Diarrhea as defined by Bristol stool } \\
\text { form and frequency }\end{array}$ \\
\hline $\begin{array}{l}\text { Biochemical evidence of mucosal malabsorption } \\
\text { (D-xylose test, fecal fat estimation, Schilling's test for } B_{12} \\
\text { malabsorption) }\end{array}$ & $\begin{array}{l}\text { Malabsorption of two unrelated substances } \\
\text { essential for diagnosis }\end{array}$ & $\begin{array}{l}\text { Results of these tests have not been } \\
\text { reported in any study }\end{array}$ \\
\hline Abnormal small intestinal histology & Required for the diagnosis & $\begin{array}{l}\text { Has not been performed in any } \\
\text { study }\end{array}$ \\
\hline \multicolumn{3}{|l|}{ Pathogenesis } \\
\hline Possible infective agents that might predispose & Bacteria, virus, protozoa & Bacteria, virus, protozoa \\
\hline Change in gut flora and small intestinal bacterial overgrowth & Often associated & $\begin{array}{l}\text { Increasing reports among patients } \\
\text { with diarrhea-predominant IBS }\end{array}$ \\
\hline Small intestinal permeability abnormality & Demonstrated & Demonstrated \\
\hline Neurohumoral dysregulation & Demonstrated & Demonstrated \\
\hline \multicolumn{3}{|l|}{ Treatment } \\
\hline Agents used in the treatment & Antibiotics, folic acid, Vitamin $B_{12}$ & $\begin{array}{l}\text { Drugs modulating gut flora such as } \\
\text { probiotics and antibiotics may be } \\
\text { potential candidates }\end{array}$ \\
\hline
\end{tabular}

\section{THE SIMILARITY BETWEEN THE PATHOGENESIS OF TS AND PI-IBS}

Table 2 and Figures 2 and 3 summarize the similarity in the pathogenesis of PI-IBS and TS. In fact, PI-IBS and PI-MAS (TS) may be a spectrum disorder (Fig. 2) ${ }^{6}$. Both PI-IBS and PI-MAS (TS) are associated with gut dysbiosis including small intestinal bacterial overgrowth (growth of $\geq 10^{5}$ colony-forming unit [CFU] bacteria per $\mathrm{mL}$ of upper gut aspirate, $\leq 10^{5} \mathrm{CFU} / \mathrm{mL}$ but $\geq 10^{3}$ is called low-grade overgrowth) ${ }^{22}$, abnormal luminal metabolome, increased small intestinal permeability, abnormal small intestinal mucosal histology, mucosal immune activation in response to pathogenic infection by bacterial, protozoa and virus, and neurohormonal dysregulation $^{1,6}$. In TS, one of the suggested mechanisms is slowing of small intestinal motility mediated by ileal brake induced by malabsorbed fat in the ileum possibly mediated by peptide $Y Y$, neurotensin, and glucagon-like peptide ${ }^{23}$. Slowing of small intestinal motility leads to colonization of small bowel by bacteria due to stasis causing malabsorption, which further leads to 


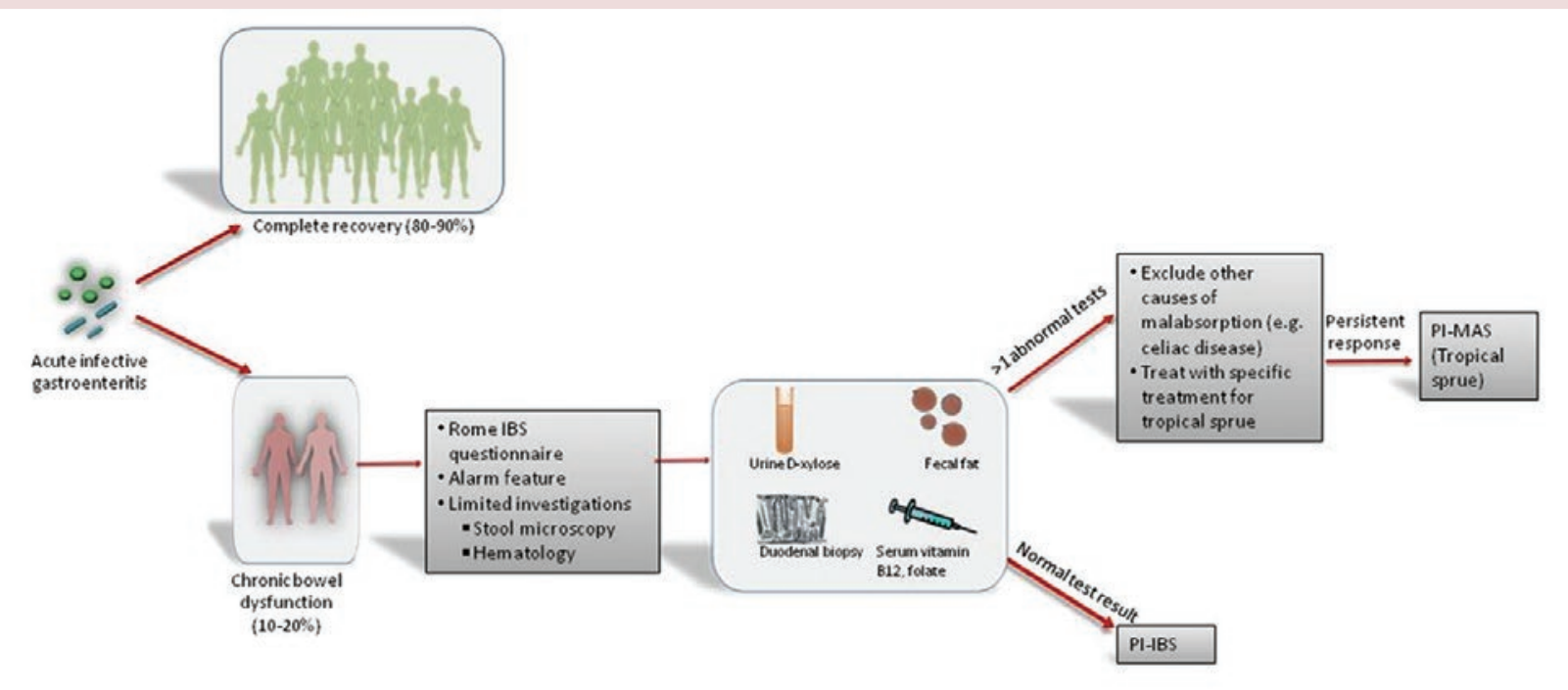

Figura 2. Schematic presentation of the outcome of acute infectious gastroenteritis and proposed algorithm to diagnose post-infection irritable bowel syndrome and post-infectious malabsorption syndrome.

steatorrhea resulting in malabsorption of fat, setting in a vicious cycle (Fig. 2) ${ }^{23,24}$. Steatorrhea may be related to multiple factors including mucosal malabsorption of fat, bacteria-splitting bile acids, and impaired enterohepatic recirculation of bile salts ${ }^{25}$. Genetic factors have been implicated in the pathogenesis of PI-IBS ${ }^{26}$. However, no study evaluated a role of genetic factors in the pathogenesis of TS. Megaloblastosis of the small intestinal epithelium due to deficiency of folic acid and Vitamin B12 has been suggested in the pathogenesis of $\mathrm{TS}^{6}$. Vegetarians are more likely to develop a deficiency of Vitamin B12 ${ }^{27}$. Recently, in an Indian rural community study, vegetarianism was shown to be associated with IBS both on univariate and multivariate analy$\operatorname{sis}^{28}$. More studies are needed on this issue.

\section{DIAGNOSTIC ALGORITHM}

Figure 1 outlines the simplified algorithm to diagnose TS among patients presenting with
PI-IBS; however, it does apply to patients presenting as a sporadic form of TS as well. In patients with chronic diarrhea, it is important to look for alarm features such as unintended weight loss and apply the Rome criteria for IBS, though fulfilling these criteria does not exclude PI-MAS7. Investigations should include hematological parameters to look for anemia including megaloblastic anemia, neutropenia and hypersegmented polymorphonuclear leukocytosis, and thrombocytopenia (Vitamin B12 deficiency), and thrombocytosis (celiac disease) ${ }^{10}$. At stool microscopy, one should look for the protozoa and parasites, which may cause malabsorption (Giardia lamblia, Strongyloides stercoralis, Capillaria philippinensis, and Coccidioides). Mucosal malabsorption should be investigated using urinary D-xylose excretion test, fecal fat estimation, serum folate, Vitamin B12 levels, and endoscopic duodenal biopsy. Since quantitative fecal fat estimation is cumbersome to perform, and hence, not available widely, alternative approaches have been evaluated $^{29}$. Since absorption of fat-soluble 
vitamins such as Vitamin A may be impaired in patients with fat malabsorption, its serum level is expected to be low in patients with steatorrhea. In fact, serum level of retinyl palmitate has been shown to be a useful test in patients with steatorrhea ${ }^{29}$. It is important to note that some of these investigations are not widely available and others are expensive and invasive; hence, clinical judgment should be exercised before undertaking these investigations. If these investigations do not indicate mucosal malabsorption, a diagnosis of PI-IBS is certain. However, if these investigations suggest the presence of mucosal malabsorption, workup for its etiology such as celiac disease, lactose malabsorption, protozoal, and parasitic infection needs to be undertaken. In the absence of another known cause of MAS and persistent response to specific treatment outlined below, a diagnosis of PIMAS (TS) may be established ${ }^{6,10}$.

\section{TREATMENT OF TS}

The mainstay of treating patients with TS includes correction of malnutrition including supplementation with vitamins, particularly Vitamin B12 and folic acid, and treatment with specific antibacterial agents. As a general rule, enteral nutrition should be preferred over parenteral and polymeric over monomeric formulae. Since most patients have secondary lactose malabsorption, milk and its products should be avoided. As previously mentioned before, several studies suggested that slowing of small bowel motility resulting from ileal brake induced by malabsorbed fat is one of the mechanisms for small intestinal bacterial colonization and overgrowth among patients with $\mathrm{TS}^{23,24}$; it is quite logical to believe that moderate fat restriction may help these patients, though evidence to prove this belief is awaited. Restriction of long-chain fatty acids may help in reducing steatorrhea. It should be replaced by medium-chain triglycerides. Coconut oil, which is rich in medium-chain fatty acids, may be helpful in reducing diarrhea ${ }^{30}$. Calorie requirement should be calculated based on the ideal body weight rather than the actual body weight. Protein and carbohydrate intake should be guided by the weight and body mass index. Patients who are very sick may require hospitalization, correction of fluid and electrolyte imbalance and supplementation of minerals such as iron, calcium, and magnesium. Hypomagnesemia may be associated with refractory hypokalemia $^{31}$. A proportion of severely malnourished patients may require parenteral nutrition; however, rapid nutritional rehabilitation may be associated with nutritional rehabilitation syndrome, which should be avoided ${ }^{32}$.

Treatment with broad-spectrum antibiotics is the mainstay of the treatment of patients with TS as it is associated with small intestinal bacterial colonization and overgrowth ${ }^{23}$. Antibacterial agents that have been tried in patients with TS include tetracycline, doxycycline, and cotrimoxazole ${ }^{6}$. Although rifaximin, a gut-specific broad-spectrum non-absorbable antibiotic, is quite popular currently to treat dysbiosis including small intestinal bacterial overgrowth, there are hardly any data on the efficacy of this antibiotic among patients with TS. A single randomized controlled trial evaluating the use of rifaximin among children with tropical enteropathy did not find it useful ${ }^{33}$. Treatment with antibiotics has been shown to improve folate and Vitamin B12 absorption in addition to improvement in absorption of other nutrients and symptom resolution ${ }^{34}$. Antibiotics 


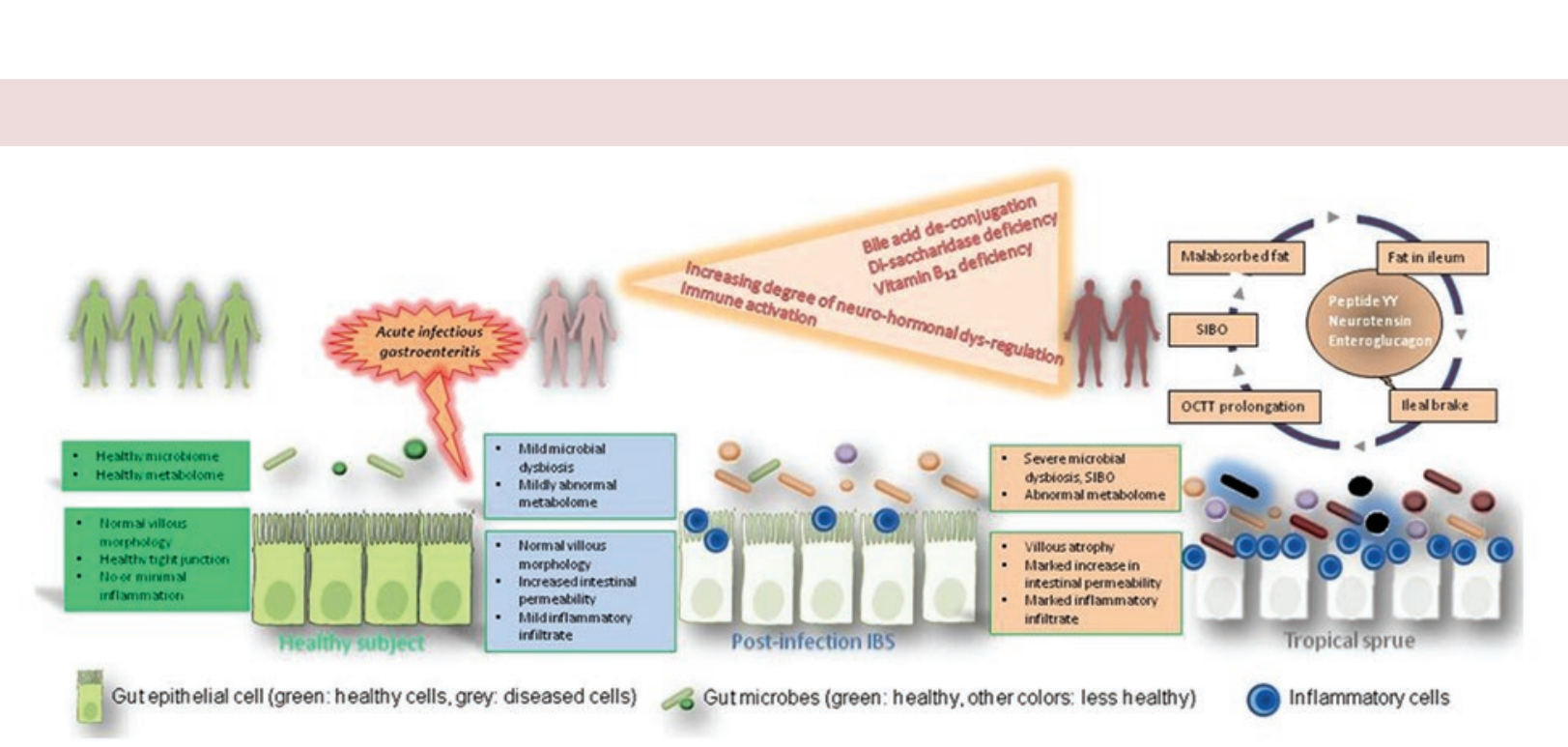

Figure 3. Outline of the pathogenesis of post-infectious malabsorption syndrome (tropical sprue) and post-infection irritable bowel syndrome showing that the two conditions have considerable overlap in terms of pathogenesis. SIBO: small intestinal bacterial overgrowth, OCTT: orocecal transit time.

are generally given for a prolonged period of time, typically for 2 months. Folic acid and Vitamin B12 supplementation, on the other hand, is given over a longer period of time, typically for 6 months. Most patients recover with proper dietary management, antibiotics, and supplementation with folic and Vitamin B12. Although recurrence is not common, recurrences do recover with retreatment as has been documented among patients with IBS ${ }^{35}$. In one study, it has been shown that the patients with TS having persistently abnormal small intestinal permeability in spite of clinical recovery gain lesser body weight and continue to have more frequent loose stool than those in whom abnormal small intestinal permeability completely normalized ${ }^{36}$.

\section{CONCLUSION AND FUTURE DIRECTION}

Following acute infectious gastroenteritis, about a $10^{\text {th }}$ to one-third patients may continue to experience bowel dysfunction, currently, named as PI-IBS if it fulfills the Rome criteria. However, TS, a forgotten disease primarily described in the underdeveloped world in the past seems to resurface even in the developed world. Current evidence suggests that about $9 \%$ of patients diagnosed with PI-IBS using Rome criteria may have PI-MAS (epidemic form of TS) when appropriate investigations are undertaken to look for mucosal malabsorption. Even the current Rome working party recognized this and suggested that TS needs to be looked for in a subset of patients with socalled PI-IBS (those with severe and alarm symptoms and weight loss) $)^{7}$. This is perhaps a paradigm shift. What is the importance of it? It clearly challenges the conventional concept that suggested that IBS is primarily functional with important psychological basis and suggests that at least some patients of IBS may have an organic basis. This is rather in line with current Rome IV perspective that suggested to remove the "functional" stigma 
TABLE 3. Criteria for diagnosis of post-infection IBS*

Acute onset Rome criteria positive IBS (in the absence of history of prior IBS) developing after an infectious illness characterized by two or more of the followings

Diarrhea

Vomiting

Fever

Demonstration of enteropathogens of stool culture

*We proposed that exclusion of mucosal malabsorption by approprate investigations including small intestinal histology be added to these criteria IBS: irritable bowel syndrome

of these disorders ${ }^{37}$. In fact, the importance of multidimensional clinical profile (MDCP), suggested in Rome IV, cannot be underestimated $^{38}$. According to MDCP, in addition to assigning diagnostic categories such as IBS, functional constipation, subtyping (e.g., constipation or diarrhea predominant), severity assessment, psychological, and physiological evaluation are needed to manage patients. This means that with time not only would PI-IBS be recognized more and more but also PI-MAS be recognized among patients with PI-IBS ${ }^{38}$. This would help clinicians to offer specific treatment to these patients. This may also help to extrapolate knowledge on the treatment of TS to managing some patients with IBS, hitherto wrongly thought to be primarily psychological in origin, by peripherally directed therapies.

\section{Current literature on the link between TS and} PI-IBS is limited to only a few studies; more studies both from the tropical and temperate countries are needed. Mucosal malabsorption may be an underlying mechanism in a subset of IBS, particularly the one with diarrheapredominant subtype, particularly following acute infectious gastroenteritis (PI-IBS). It is, therefore, suggested that mucosal malabsorption should be excluded by appropriate investigations including small intestinal histology before a diagnosis of PI-IBS is made (Table 3). Furthermore, randomized controlled trials are needed to evaluate the efficacy of treatment directed to TS in patients with PI-IBS.

\section{REFERENCES}

1. Ghoshal UC, Gwee KA. Post-infectious IBS, tropical sprue and small intestinal bacterial overgrowth: the missing link. Nat Rev Gastroenterol Hepatol. 2017;14:435-41

2. Stewart GT. Post-dysenteric colitis. Br Med J. 1950;1:405-9.

3. Chaudhary NA, Truelove SC. The irritable colon syndrome. A study of the clinical features, predisposing causes, and prognosis in 130 cases. Q J Med. 1962;31:307-22.

4. Gwee KA, Graham JC, McKendrick MW, et al. Psychometric scores and persistence of irritable bowel after infectious diarrhoea. Lancet. 1996;347:150-3.

5. Ghoshal UC, Ranjan P. Post-infectious irritable bowel syndrome: the past, the present and the future. J Gastroenterol Hepatol. 2011;26 Suppl 3:94-101.

6. Ghoshal UC, Srivastava D, Verma A, Ghoshal U. Tropical sprue in 2014: the new face of an old disease. Curr Gastroenterol Rep 2014;16:391.

7. Barbara G, Grover M, Bercik P, et al. Post-infection irritable bowel syndrome: rome Foundation working team report. Gastroenterogy. 2018; In press.

8. Schwille-Kiuntke J, Mazurak N, Enck P. Systematic review with metaanalysis: post-infectious irritable bowel syndrome after travellers' diarrhoea. Aliment Pharmacol Ther. 2015;41:1029-37.

9. Klem F, Wadhwa A, Prokop LJ, et al. Prevalence, risk factors, and outcomes of irritable bowel syndrome after infectious enteritis: a Systematic review and meta-analysis. Gastroenterology. 2017;152:1042-540

10. Ghoshal UC, Mehrotra M, Kumar S, et al. Spectrum of malabsorption syndrome among adults \&amp; factors differentiating celiac disease \&amp; tropical malabsorption. Indian J Med Res. 2012;136:451-9.

11. Dutta AK, Balekuduru A, Chacko A. Spectrum of malabsorption in India-tropical sprue is still the leader. J Assoc Physicians India. 2011;59:420-2.

12. Yadav P, Das P, Mirdha BR, et al. Current spectrum of malabsorption syndrome in adults in India. Indian J Gastroenterol. 2011;30:22-8.

13. Ayrey F. Outbreaks of sprue during the burma campaign. Trans R Soc Trop Med Hyg. 1947;41:377-406.

14. Sheeby TW. Digestive disease as a national problem. VI. Enteric disease among united states troops in vietnam. Gastroenterology. 1968;55:105-12.

15. Lim ML. A perspective on tropical sprue. Curr Gastroenterol Rep. 2001;3:322-7.

16. Mathan VI, Baker SJ. Epidemic tropical sprue and other epidemics of diarrhea in south indian villages. Am J Clin Nutr. 1968;21:1077-87.

17. Rajendra S, Baharain SR, Karim N, Ho JJ, Kutty K. Ethnic disparity in the prevalence of partial villous atrophy and post-infective tropical malabsorption. J Gastroenterol Hepatol. 2004;19:472-4.

18. McCarroll MG, Riddle MS, Gutierrez RL, Porter CK. Infectious gastroenteritis as a risk factor for tropical sprue and malabsorption: a Case-control study. Dig Dis Sci. 2015;60:3379-85.

19. Rahman MM, Ghoshal UC, Sultana S, et al. Long-term gastrointestinal consequences are frequent following sporadic acute infectious diarrhea in a tropical country: a prospective cohort study. J Gastroenterol Hepatol. 2017;32:153.

20. Wood GM, Gearty JC, Cooper BT. Small bowel morphology in british indian and afro-caribbean subjects: evidence of tropical enteropathy. Gut. 1991;32:256-9.

21. Louis-Auguste J, Kelly P. Tropical enteropathies. Curr Gastroenterol Rep 2017;19:29.

22. Ghoshal UC, Ghoshal U. Small intestinal bacterial overgrowth and other intestinal disorders. Gastroenterol Clin North Am. 2017;46:103-20. 
23. Ghoshal UC, Ghoshal U, Ayyagari A, et al. Tropical sprue is associated with contamination of small bowel with aerobic bacteria and reversible prolongation of orocecal transit time. J Gastroenterol Hepatol. 2003;18: 540-7.

24. Ghoshal UC, Kumar S, Misra A, Choudhuri G. Pathogenesis of tropical sprue: a pilot study of antroduodenal manometry, duodenocaecal transit time and fat-induced ileal brake. Indian J Med Res. 2013;137:63-72.

25. Aubert A, Gornet JM, Hammel P, et al. Diffuse primary fat replacement of the pancreas: an unusual cause of steatorrhea. Gastroenterol Clin Biol. 2007;31: 303-6.

26. Villani AC, Lemire M, Thabane M, et al. Genetic risk factors for postinfectious irritable bowel syndrome following a waterborne outbreak of gastroenteritis. Gastroenterology. 2010;138:1502-13.

27. Pawlak R, Parrott SJ, Raj S, Cullum-Dugan D, Lucus D. How prevalent is vitamin B(12) deficiency among vegetarians? Nutr Rev. 2013;71:110-7.

28. Ghoshal UC, Singh R. Frequency and risk factors of functional gastro-intestinal disorders in a rural Indian population. J Gastroentezrol Hepatol. 2016;32:378-87.

29. Raman M, Fenton T, Crotty P, et al. A novel method to identify fat malabsorption: the serum retinyl palmitate test. Clin Chim Acta. 2015;438:103-6.

30. Shilling M, Matt L, Rubin E, et al. Antimicrobial effects of virgin coconut oil and its medium-chain fatty acids on clostridium difficile. J Med Food 2013;16:1079-85.
31. Jain RS, Gupta PK, Agrawal R, Kumar S, Khandelwal K. An unusual case of dengue infection presenting with hypokalemic paralysis with hypomagnesemia. J Clin Virol. 2015;69:197-9.

32. Solomon SM, Kirby DF. The refeeding syndrome: a review. JPEN J Parenter Enteral Nutr. 1990;14:90-7.

33. Trehan I, Shulman RJ, Ou CN, Maleta K, Manary MJ. A randomized, doubleblind, placebo-controlled trial of rifaximin, a nonabsorbable antibiotic, in the treatment of tropical enteropathy. Am J Gastroenterol. 2009;104:2326-33.

34. Tomkins AM, Smith T, Wright SG. Assessment of early and delayed responses in vitamin B12 absorption during antibiotic therapy in tropical malabsorption. Clin Sci Mol Med Suppl. 1978;55:533-9.

35. Lembo A, Pimentel M, Rao SS, et al. Repeat treatment with rifaximin is safe and effective in patients with diarrhea-predominant irritable bowel syndrome. Gastroenterology. 2016;151:1113-21.

36. Kumar S, Ghoshal UC, Jayalakshmi K, et al. Abnormal small intestinal permeability in patients with idiopathic malabsorption in tropics (tropical sprue) does not change even after successful treatment. Dig Dis Sci. 2011;56:161-9.

37. Drossman DA. Functional gastrointestinal disorders: history, pathophysiology, clinical features and rome IV. Gastroenterology. 2016.

38. Drossman DA. Guidelines for use of the multi-dimensional clinical profile. In: Multi-Dimensional Clinical Profile (MDCP) for the Functional Gastrointestinal Disorders. $1^{\text {st }}$ ed. North Carolina; Rome Foundation; 2015. p. 7-14. 